Document downloaded from:

http://hdl.handle.net/10251/77125

This paper must be cited as:

Pastor Soriano, JV.; García Oliver, JM.; Pastor Enguídanos, JM.; Ramírez Hernández, JG. (2011). Ignition and combustion development for high speed direct injection diesel engines under low temperature cold start conditions. Fuel. 90(4):1556-1566.

doi:10.1016/j.fuel.2011.01.008.

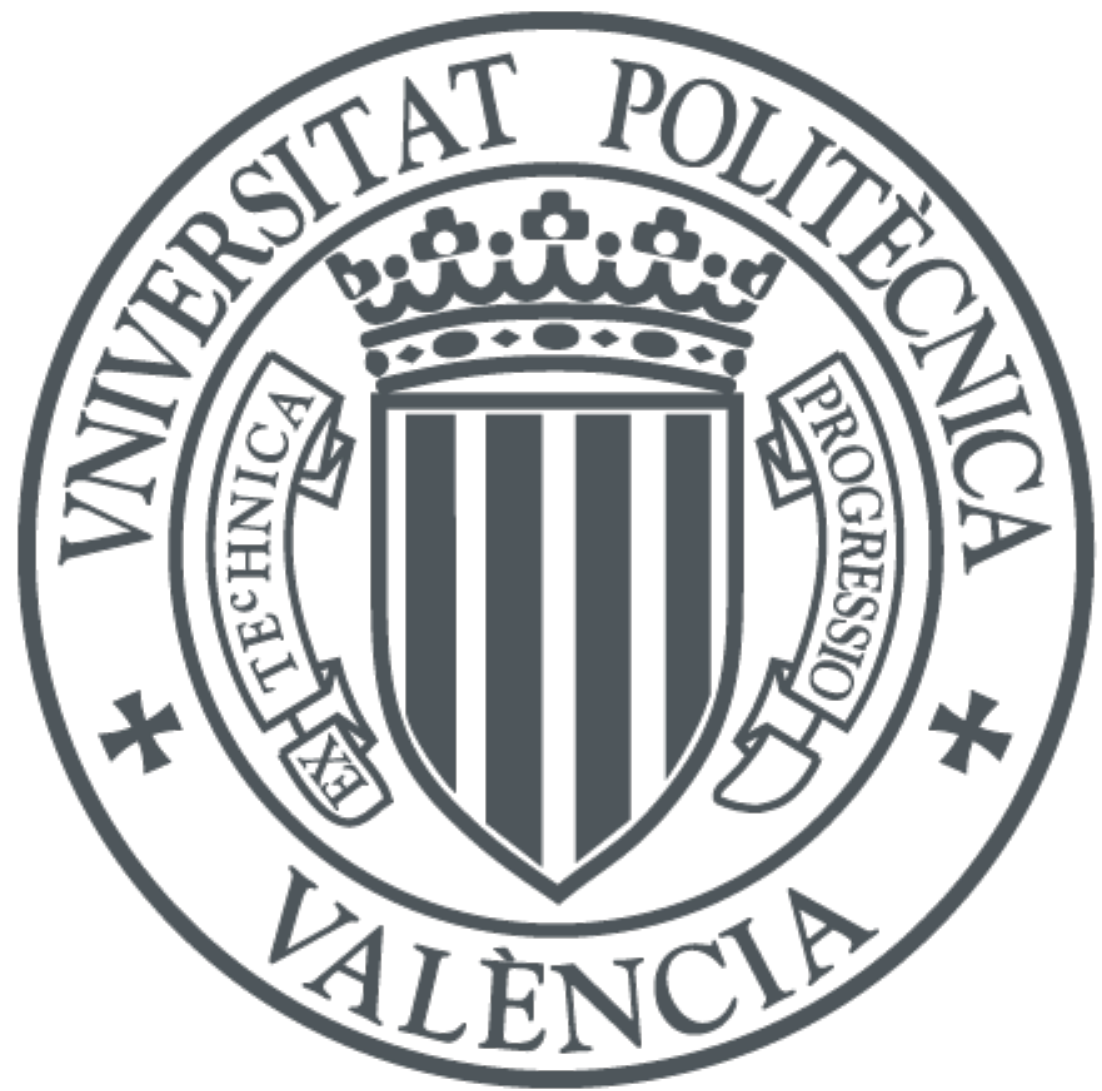

The final publication is available at

http://dx.doi.org/10.1016/j.fuel.2011.01.008

Copyright Elsevier

Additional Information 


\title{
Ignition and combustion development for high speed direct injection diesel engines under low temperature cold start conditions
}

\author{
J.V. Pastor, J.M. García-Oliver*, J.M. Pastor, J.G. Ramírez-Hernández \\ CMT Motores Térmicos - Universidad Politécnica de Valencia \\ Camino Vera $s / n$ - 46022 Valencia, Spain. \\ Telephone: +34 96387r650, Fax: +34 963877659
}

\begin{abstract}
Diesel engine cold start is an important issue for current technology at low (below $0^{\circ} \mathrm{C}$ ) temperatures and for future applications. The aim of this work is to develop a description of how, when and where does fuel spray ignition occur in a glow-plug assisted engine under simulated low temperature cold start conditions. In-cylinder pressure analysis is combined with high speed visualization in an optical engine. A pilot plus main injection strategy is used. Visualization results show that pilot ignition occurs in the vicinity of the glow plug, and strongly influences main combustion initiation. Main combustion starts from the pilot flame, and propagates to the rest of the combustion chamber showing a strong visible reaction zone. After end of main injection, the rapid leaning of the mixture suppresses the strong radiation, and $\mathrm{OH}$ radiation is observed to progress to the rest of the combustion chamber. The combustion process shows a strong scattering, which has been quantified
\end{abstract}

\footnotetext{
${ }^{*}$ Corresponding author

Email address: jgarciao@mot.upv.es (J.M. García-Oliver )
} 
by combustion parameters. At higher rail pressures scattering increases, which eventually inhibits combustion initiation. However, if ignition occurs at higher rail pressures, cycle performance is better.

Key words: Diesel engine, Cold start, High speed imaging, Ignition aid, Combustion analysis, Pilot injection.

\section{Introduction}

In spite of all the improvements made in diesel technology to the date, starting at low (below $0^{\circ} \mathrm{C}$ ) ambient temperatures is still a problem which has not been properly solved. Low ambient temperatures result in low peak compression temperature, which causes poor vaporization. Low peak pressures are also achieved due to the high blow-by level as a result of engine block temperature, low engine speed and low intake pressure. Such conditions lead to a very poor fuel air mixing process which, in addition to the poor vaporization, can inhibit fuel ignition under this particular and strongly transient engine situation provoking unburnt hydrocarbon emissions ([1]). In order to promote ignition, air temperature within the combustion chamber is increased by means of ignition aids, as intake heaters or glow plugs [2, 3]. For current automobile diesel engines these aids become necessary for temperatures below $-11^{\circ} \mathrm{C}[4]$ and for future applications with reduced compression ratio $([4,5,6,7])$ these aids are necessary below $10^{\circ} \mathrm{C}[4]$.

Most of the studies on low temperature cold start are focused on trial-anderror procedures and carried out in climatic chambers, but recently they have become more systematic aiming at engine cold start optimization. Studies performed on climatic chambers $([3,8,9,10])$ have certainly delivered valu- 
able information but several measurement uncertainties and the incapability of using extra diagnostic tools have prevented from making a detailed explanation of this combustion process. Laget et al [6] show a more systematic approach to the problem in which in-cylinder analysis, endoscopic visualization and CFD modeling are coupled in order to identify the pre-glowing glow plug duration, nozzle tip protrusion, injector spray angle and cranking speed as key parameters with influence on startability. Later, a more detailed analysis of the combustion sequence have been presented by Perrin et al [11], in which the location of the first ignition spots are shown to appear in the vicinity of the glow plug, together with the influence of some other parameters like swirl motion and injection pressure. Similar work has been presented by Chartier et al [12], who show how combustion starts close to the glow plug and does not spread to the whole chamber.

All previous papers evidence the current interest of engine community to understand and optimize engine performance under cold start conditions. Most of these works address the optimization of a particular engine or vehicle, studying the effect of specific engine parameters on cold start ease. But only few of them try to go deeper into an explanation on the sequence of events leading to successful combustion initiation. The main objective of this paper is to give a detailed description of the combustion process within the combustion chamber and the phenomena that lead to combustion initiation. The study will be performed in a single-cylinder optical engine that has been adapted to simulate in-cylinder conditions similar to those of a real engine operating at low temperature cold start [13]. After this introduction, the experimental and calculation tools and methodology used for the study are 
presented. Then, an evaluation of combustion scattering is made, followed by a general description of the combustion event. Later on, the effect of rail pressure on combustion is evaluated, and finally a discussion on the controlling parameters for low temperature cold start combustion is made. Finally, the main outcomes of this work are presented.

\section{Tools and methodology}

This section presents a description of the experimental and theoretical tools employed for this study. Experimental information has been obtained in a specially adapted facility in which in-cylinder cold start conditions can be reproduced in an optical single cylinder engine at room temperature. Theoretical tools consist on chemical kinetics and CFD simulations that have been carried out in order to help understand the experimental results in terms of physical variables.

\subsection{Experimental facility}

This sub-section is a brief summary of the engine description, the solution adopted in order to reach cold start conditions and a description of the fuel injection system. A more detailed explanation about the facility adaptation and its capabilities has already been presented in [13].

\subsubsection{Engine description}

The optical engine used in the present study, sketched in Figure 1, is a 4 -valve and $0.55 l$ displacement single cylinder engine. The engine is equipped with an elongated piston with a cylindrical bowl, with dimensions 
of $45 x 16 \mathrm{~mm}$ (diameter $x$ depth), which allows optical access to the combustion chamber through a sapphire window placed in its bottom. Below the piston bowl, an elliptical UV mirror is placed on the cylinder axis. And, in front of the mirror, the high speed camera is positioned to record radiation that comes from the combustion chamber.

The facility has been modified to reproduce the first injection cycle of the starting sequence of a passenger car engine at $-20^{\circ} \mathrm{C}$. Specifically, thermodynamic conditions within the combustion chamber and low engine speed can be reproduced systematically. In order to reach the same peak in-cylinder temperature, the compression ratio has been reduced (16:1 to $8: 1$ ) and intake temperature has been controlled at $30^{\circ} \mathrm{C}$. Compression ratio has been reduced by placing an aluminum piece (shown in Figure 1), with $42 \mathrm{~mm}$ height and internal diameter slightly larger than the engine bore, between the cylinder head and the engine block. Peak in-cylinder pressure has been set controlling the intake pressure. Finally, the electronics of the electrical motor have been modified so that stable operation at $250 \mathrm{rpm}$ is ensured.

A standard glow plug [2] (Figure 1) is used for the study. At the standard configuration, the tip protrudes $3 \mathrm{~mm}$ into the combustion chamber from the cylinder head plane, it is located at $11.5 \mathrm{~mm}$ from the cylinder axis and it is operated at a constant nominal tension of $11 \mathrm{~V}$.

\subsubsection{Fuel injection system}

A common rail injection system with piezo injectors is operated externally to ensure stable behavior, avoiding uncertainties associated to corrections made by the ECU. The injector used is equipped with a microsac nozzle with seven holes (with a nominal diameter of $0.142 \mathrm{~mm}$ ). It is centered in 
the cylinder and vertically mounted as shown in Figure 1. In that way, spray orientation with respect to the glow plug can be modified by rotating the injector around its axis. For this study, one of the sprays has been oriented at $15^{\circ}$ from the glow plug in clockwise direction. Under this configuration, the minimum distance between the glow plug surface and the spray has been estimated to be $2.3 \mathrm{~mm}$.

Injection is performed at a reduced frequency (one injection every 40 cycles) to avoid engine temperature increase, speed instability in case of ignition and to reduce window fouling. Each test consists of 20 to 30 injection cycles recorded under the same engine conditions.

\subsubsection{Conditions of the study}

For the tests presented in the following sections basic engine conditions will remain unchanged: engine speed $250 \mathrm{rpm}$; intake air temperature $30^{\circ} \mathrm{C}$, with which $345^{\circ} \mathrm{C}$ are obtained as peak in-cylinder temperature; oil, fuel and water temperatures are fixed at $30^{\circ} \mathrm{C}$ and intake pressure is set to reach target peak compression pressure (27 bar). Two levels of rail pressure, similar to those reached during the starting sequence in a real engine at low temperature, have been tested, namely 250 and 370 bar. The former is the lowest possible value for stable behavior at short injection pulses. And the latter is a value close to the limit above which ignition can not been achieved. The injection strategy consists of two separated pulses. In the first one, a small amount of fuel is delivered at $0 C A D$ and in the second one, $24 \mathrm{mg}$ of fuel are injected at $5 C A D$. 


\subsection{In-cylinder pressure analysis}

The tool employed to perform the combustion analysis is a one zone model proposed by Lapuerta [14] (CALMEC). This diagnosis tool uses the measured in-cylinder pressure as main input. Then, the first law of thermodynamic is applied between IVC and EVO considering the chamber as an open system because of blow-by and fuel injection. The ideal gas equation of state is used to calculate the mean gas temperature in the chamber. Along with these two basic equations, several sub-models to calculate instantaneous volume,

heat and mass transfer are used. Specifically, Woschni's equation is used to calculate the heat transfer coefficient [15].

The model main result is the ROHR. But the temporal evolution of other parameters like the HRL (defined as the integral of ROHR and normalized with respect to its maximum) or the mean gas temperature can be calculated. Temporal resolution for these variables depends on the crank angle encoder configuration $(0.5 C A D)$. Global information on each cycle can be obtained, such as IMEP, SOC and CE. SOC is defined as the crank angle position where the beginning of the strong rise in ROHR due to combustion is detected. And $\mathrm{CE}$ is defined as the ratio between the total energy released in one cycle and the total energy available in the fuel injected. It is calculated by equation 1 :

$$
C E=\frac{100}{m_{f} \cdot L H V} \cdot \int_{I V C}^{E V O} \operatorname{ROHR}(\alpha) d \alpha
$$

where the energy released in one cycle is the integral of the ROHR calculated between IVC and EVO, $m_{f}$ is the mass of fuel injected and LHV is the fuel lower heating value. 


\subsection{Image acquisition and post-processing}

Images were recorded using a Photron Ultima APX I2 high speed image system with two camera heads. They are equipped with 10-bit CMOS sensors and all images in the study have been recorded at an acquisition frequency of $6000 \mathrm{fps}$ with a $512 x$ 512-pixel image size. The intensified camera head was used to record $\mathrm{OH}$ chemiluminescence $([16,17])$ and it was coupled with a $100 \mathrm{~mm}$ focal length UV objective with a $310 \mathrm{~nm}$ wavelength interference filter (10 nm FWHM); camera gain was set to its maximum value and the intensifier gate time to $150 \mu \mathrm{s}$. The non-intensified camera head, coupled with a $135-400 \mathrm{~mm}$ focal length Helmut APO objective with a number 1 close up lens, was used to record broadband natural luminosity in two ways. First, a set of images was acquired illuminating with an external light source and with long exposure time $(166 \mu s)$ in order to visualize at the same time the Mie-scattering from the liquid spray and flame radiation coming

from the first ignition locations. Secondly, combustion radiation images have been recorded without external illumination and camera settings have been adjusted to avoid sensor saturation.

In order to simplify combustion analysis, time resolved parameters are obtained for every image sequence by means of post-processing. First, segmentation is performed for every single image by calculating a threshold value which is equal to the minimum digital level in the image plus $15 \%$ of the difference between the maximum and the minimum. This percentage has been chosen as a compromise to eliminate light reflected on the liquid spray and the chamber walls without losing much information from the combustion event. After segmentation, the digital levels of all pixels containing the com- 
bustion radiation (with digital levels above the threshold) are accumulated in a single parameter named $I_{\text {cumul }}$. Additionally, as shown in Figure 2, IL is defined as the integral of the $I_{\text {cumul }}$ plot and LD as the time between SoI and the first luminosity detection.

\subsection{Modeling tools}

\subsubsection{Chemical kinetics}

Calculations have been performed by means of CHEMKIN software [18]. An n-Heptane detailed kinetic mechanism [19], considered as suitable diesel fuel surrogate in terms of ignition characteristics, has been solved for constant pressure homogeneous reactor conditions. Simulations have spanned a range between 600 and $1200 K$ in terms of initial temperatures, and 0.2 to 2 in terms of fuel equivalence ratio. Pressure has been set to 27 bar for all cases (in-cylinder pressure at SoI). Ignition delay has been defined as the time period from start of calculations until an increase of $400 \mathrm{~K}$, over the initial temperature, is detected.

\subsection{2. $C F D$ calculations}

Simulations have been performed by means of StarCD [20] to understand the physical processes related to fuel evaporation and mixture formation from the SoI until flame appearance. For this reason, no combustion model has been used. The computational grid comprised the combustion chamber and crevice volumes as well as the glow-plug. Typical grid size is around $1 \mathrm{~mm}$, and it is further refined around the glow plug region as shown in Figure 3. A standard lagrangian approach (DDM[21]) is used for fuel spray modeling. Huh-Gosman [22] and Reitz-Diwakar [23] models are applied for primary and 
secondary break-up, respectively. Spray outlet boundary conditions are obtained from injection mass flow rate and momentum flux measurements. Fuel physical properties are given by the so-called DF1 [24] diesel fuel surrogate. Turbulent flow is modeled with the RNG $k-\epsilon$ model and standard wall functions. Both, initial conditions at IVC and wall temperatures, have been estimated by means of CALMEC [14] from experimental data. A wheel-flow velocity profile with swirl number 2.2 is used for air-flow initialization, and a constant temperature boundary condition $(1373 \mathrm{~K})$ is applied on the glow plug surface.

\section{General description of the combustion event}

As a first approximation to the problem, this section aims to show the main characteristics of diesel combustion process under cold star conditions. First, an overall view to the combustion event is presented, by using a full pilot + main injection strategy. Then, pilot injection and main combustion are described separately in order to make emphasis on the peculiarities of these different processes.

\subsection{Combustion description}

A typical test using the baseline strategy at low injection pressure is shown in Figure 4, in which CALMEC global cycle parameters are plotted as a function of the repetition number. In this plot, differences as big as 1 bar can be observed in IMEP between two repetitions (0 and 4 for example). With regard to SOC, the maximum differences are in the order of $1.5 C A D$. This difference may be considered significative since it may shift the start of combustion from being close to SoI to be near the end, which could have 
an effect on combustion development. Another remarkable characteristic of the cold start combustion is the low CE values (around 50\%). This fact is quite different from conventional diesel combustion [25] where all the energy within the fuel is released during combustion, so $\mathrm{CE}$ is close to $100 \%$. By contrast, under cold start conditions, low temperature impedes evaporation, which in turn makes it impossible to burn all the fuel. Furthermore, a linear relationship with IMEP $\left(R^{2}=0.96\right)$ is observed, cycles with high IMEP correspond to cycles with high $\mathrm{CE}$ and vice-versa. This confirms that any improvement in fuel combustion will directly improve engine performance under cold start conditions.

Figure 5 shows a sequence of representative images of a high performance combustion cycles. The temporal sequence of events starts at $133 \mu s$, when pilot injection has already started. During pilot injection, sprays penetrate rapidly into the chamber reaching the bowl wall within a short time (at $300 \mu \mathrm{s}$ ). From this moment until $E o I_{\text {pilot }}$, liquid fuel is seen to impinge on the walls. After the EoI, at $633 \mu s$, liquid fuel is observed to vanish from the injector toward the chamber walls. Up to this moment, no reaction has been observed in any of the sprays. Only some time after $E o I_{\text {pilot }}$, at $1633 \mu \mathrm{s}$, some small radiation spots are detected by the camera on the glow plug area. Subsequent images show how these ignition sites travel toward the bowl wall and a small flame is formed. Due to the location of the first luminosity spot, and also to the later path followed by this small flame, it can be ensured that the fuel burnt corresponds to the spray closest to the glow plug. The pilot flame remains attached to the bowl wall during the period between both injection pulses. Due to the poor evaporation conditions, this may mean 
that the flame is burning liquid fuel deposited on the walls. Main injection combustion starts as soon as the closest spray to the glow plug reaches the pilot flame (at $4467 \mu s$ ). The flame starts propagating both in down- and up-swirl directions, as shown in the image acquired at $5467 \mu s$. The other sprays, illuminated by the light source or by the flame radiation, are seen to impinge on the bowl wall, and some liquid fuel is seen to flow on the window wall toward the center of the image. After a short period (at $5800 \mu s$ ), the initial flame has spread over the two adjacent sprays, and burns the fuel in those zones. At this time, the main injection finishes but the flame can still be seen to propagate a little further in subsequent instants $(6800 \mu s)$. From here and on, camera saturation prevents from understanding any further progress in combustion.

\subsection{Pilot combustion description}

Due to the proven relevance of pilot ignition for achieving an early and controlled SOC, in this sub-section single pilot injection tests are presented without the main pulse. No illumination source was used and the camera exposure time was reduced so that the camera dynamic range is used to quantify flame radiation without saturation. By means of these tests, the questions of how, when and where pilot injection ignites and progresses are addressed.

Main characteristics of pilot ignition and development can be observed in Figure 6. It is observed how not all the repetitions show luminosity, e.g. cycles 5 and 14 do not reach the conditions to release visible light. This shows that cycle dispersion observed for the full injection strategy is also occurring during the pilot injection. It is also shown that the first luminosity 
spot always happens well after EoI pilot as already observed in Figure 5 and LD values are scattered between a minimum value, around $1400 \mu s$, and a maximum of $2500 \mu \mathrm{s}$. No radiation is observed later, which indicates that pilot ignition is more likely to occur during a certain time period, otherwise combustion may be inhibited (e.g. repetitions 5 and 14). Similarly, IL from pilot flame also exhibits strong scattering with certain correlation with LD. Repetitions with longest LD generally show lowest IL, and vice-versa. As for the longest ignition delay $(2500 \mu s)$ piston is still close to TDC (around $4 C A D)$, this is not due to piston expansion cooling but to the availability of fuel close to the glow plug. Regarding ignition location, first luminosity spots appear always on the glow plug side closest to the spray.

\subsection{Main combustion description}

Visualization tests of main combustion are presented in Figure 7. The propagation of the main combustion for the repetition zero of the same test presented before in Figure 4 is shown. The combustion sequence begins with the SOC at $4770 \mu s$, which is the moment when the main injection pulse reaches the pilot flame. Subsequently, the visible flame grows in size and luminosity $\left(I_{\text {cumul }}\right)$, which also corresponds to a more intense heat release (ROHR). During this initial period, flame propagation is sustained by the injection event from the initial spray (1) to the adjacent ones (2 and 7) and toward the center of the chamber (images at 6437 and $6937 \mu s$ ). After EoI, flame propagation interacts with the decelerating flow; thus both, ROHR and $I_{\text {cumul }}$, increase at a lower rate until the first peak in ROHR trace is reached. Later, at $7937 \mu s$, flame appearance is not as compact as before and an increasing number of unconnected bright zones can be seen over the 
previous flame limits (between sprays 3 and 6). Then, at $9770 \mu s$, these highly disperse bright zones extend to the zones where combustion was not seen before. This may be an indication of non-visible chemical activity out of the compact flame, since during this period the ROHR still reaches a second maximum. Meanwhile, the bulk compact flame is observed in the zone where ignition started (between sprays 2 and 7 ). In the later part of the cycle, the ROHR decreases and the combustion seems to be located both at the initial zone where combustion appeared and also attached to the bowl wall forming a kind of flame ring that lasts for a long period. This is most probably due to liquid fuel that has been deposited on the walls after impingement and it is being burnt by diffusion during the expansion stroke.

To further clarify the last part of the combustion sequence Figure 8 shows $\mathrm{OH}$ chemiluminiscence images together with broadband luminosity images. The first pair of images corresponds to $S O C$, at $4916 \mu s$, in which luminosity is only observed in the broadband radiation images, probably due to limitations in sensitivity for $\mathrm{OH}$ radiation. The second pair, which corresponds to the moment at which the main injection is finishing $(7572 \mu s)$, shows that the reaction structure in both pictures is very similar, with a relatively compact flame that is spreading across the combustion chamber. Later on, the bulk visible flame is seen to stop growing, and the less compact zones progress throughout the remaining parts of the combustion chamber. Nevertheless, $\mathrm{OH}$ radiation images do show the flame spreading over zones beyond the visible flame, while still keeping a relatively compact appearance. This is shown in the last two pairs of images, indicating that there exists a combustion process that sweeps the combustion chamber. During the injection event, 
this process emits a strong radiation, most probably due to soot presence, but after EoI the further progress of this combustion zone emits non-visible radiation.

\section{Effect of rail pressure on combustion}

Results at 370 bar, presented in this section, will be compared with previous results at 250 bar, shown in Figures 4 and 7. The first comparison is made in terms of combustion global cycle parameters. By comparing both tests important differences arise. First, there is a clear difference in terms of combustion probability. At 250 bar, all 30 repetitions show positive work. Meanwhile, at 370 bar, 5 out of 30 cycles show IMEP lower than zero, evidencing ignition problems at higher rail pressure. Secondly, if combustion occurs, IMEP and CE are significatively higher at 370 bar. This seems to be a consequence of higher velocity or momentum induced by injection, which improves the mixing process and therefore enables the evaporation and mixing of more fuel throughout the whole cycle. Finally, there is a small difference in terms of SOC which is in the order of the crank angle encoder resolution. At 370 bar SOC is detected around 0.5 CAD earlier for some cycles. This is most probably due to the fact that at higher rail pressure the spray reaches the pilot flame approximately $200 \mu s$ earlier.

The next comparison is presented in terms of propagation of the main combustion. The temporal evolution of one cycle with high IMEP at 370 bar is shown in Figure 10 as shown in Figure 7 for the cycle at 250 bar. The main combustion characteristics (initiation of main combustion at the spray the closest to the glow plug, spatial development of visible flame during injection, 
later deceleration after EoI and final drop in ROHR) are coincident with the results at 250 bar. Differences are related to the duration and intensity of the combustion process. At 370 bar, combustion is shorter in duration, in agreement with the shorter injection pulse, but more intense as well. This is evidenced in the slope of both, ROHR and $I_{\text {cumul }}$, traces and their peak values.

\section{Effect of injected mass and rail pressure on pilot injection}

The previous sections have pointed out the role of pilot injection as the main ignition promoter and the effect of rail pressure on main combustion development. To further clarify the effect of injection pressure on cold start combustion this section presents a study of two levels of rail pressure (250 and 370 bar ) and three different amounts of injected mass $(0.43,0.86$ and $1.71 \mathrm{mg}$ per orifice). Injected mass has been expressed in terms of injected mass per orifice because it is already known that ignition occurs only due to the spray closest to the glow plug. Nominal injection conditions (Section 3.2) correspond to 250 bar rail pressure and $0.86 \mathrm{mg}$ per orifice (i.e. $6 \mathrm{mg}$ per pulse).

Within the range of injection conditions used in this study, a change in any of both, rail pressure or fuel mass involves a change in the shape of the injection rate, as shown in Figure 11. This is due to the short injection duration of the pilot pulses, for which needle never reaches full lift. Therefore, injection rate never reaches stabilization. Altogether, a change in pulse duration modifies both injected mass and momentum of the spray, whereas a change in pressure modifies only the latter variable. 
Results are shown in terms of pilot probability, which is the percentage of repetitions that show luminosity in one test, LD and IL. To start with, pilot probability is shown in Figure 12 as a function of injected mass per orifice for both levels of rail pressure. This plot shows how pilot probability decreases with increasing rail pressure and/or injected mass. In fact, at 370 bar and $1.71 \mathrm{mg}$ per orifice, only two cycles show pilot flame, evidencing the poor conditions for autoignition. Under this condition, subsequent results obtained for LD and IL (Figures 13 and 14) cannot be considered statistically significative, as confirmed by the high dispersion in the measured parameters. This decreasing trend in pilot probability confirms the results from the previous section, indicating that an increase on rail pressure actually inhibits combustion initiation for both, single or full injection strategies. In the second place, LD is plotted as a function of the injected mass per orifice for both levels of rail pressure in Figure 13. In these plots, the end of injection timing has also been included as a reference of the injection duration. This figure shows that LD increases the larger the injected mass and, in minor degree, the lower the rail pressure. It also shows that pilot ignition occurs well after the EoI for all cases. It is remarkable the fact that both characteristic times (LD and EoI) follow the same trend, i.e. LD increases with injected mass at the same rate as EoI timing does. This fact hints at the hypothesis that EoI processes may also play a role in pilot injection ignition. Recent results [26] have shown that EoI produces a fast deceleration of the spray flow, as well as a rapid leaning of the mixture. It seems that such processes may be important in the autoignition sequence. Finally, IL is shown in Figure 14 in order to quantify the overall luminosity released during one pilot injection cycle. 
This figure shows IL as a function of the injected mass per orifice for both levels of rail pressure. As observed, increasing both parameters brings about a reduction in IL, this result confirms the correlation presented in Figure 6 between short LD and high IL.

\section{Discussion on the cold start ignition mechanisms}

Chemical kinetics calculations have been carried out in order to isolate the contribution of the chemical processes on ignition. Figure 15 shows the predicted autoignition delay as a function of temperature and equivalence ratio for a constant pressure of 27 bar (in-cylinder pressure at TDC). Figure 15 shows that, at temperatures similar to those that can be reached at TDC without the glow plug (approximately $600 K$ ), autoignition delay is independent of the equivalence ratio and is longer than $10 \mathrm{~ms}$, which is well above experimental values. On the other edge of the plot, at temperatures as high as those that can be reached on the glow plug surface (near $1200 \mathrm{~K}$ ), autoignition delay decreases to a few hundred microseconds with some weak dependency on equivalence ratio. This correlates better with experimental results in which the autoignition is limited to the glow plug vicinity and the shortest LD were detected between 1200 and $1500 \mu s$.

Physical phenomena, during and after injection, have been studied by means of CFD calculations. To quantify conditions in the glow plug vicinity, local properties have been evaluated in a small volume with an approximate thickness of $1 \mathrm{~mm}$ around the glow plug. Average equivalence ratio for the vapor phase of this control volume is plotted as a function of time in Figure 16. This variable is very important both from the point of view 
of mixture formation and from the chemical kinetics point of view. For the three cases plotted, equivalence ratio shows a similar time evolution. There is minimum delay for the injected fuel to travel from the nozzle to the glow plug area. This delay decreases the higher the injection velocity, i.e. the higher the rail pressure. After this delay, there is a steep increase on equivalence ratio up to a maximum value, which is always reached after EoI. Then, equivalence ratio decreases, as the evolution is fully governed by the leaning process going on throughout the spray after EoI. These results can help explain the experimental inverse relationship found between IL and LD. For cycles where ignition occurs within a short delay (low LD), more fuel is available close to the glow plug and thus chemistry proceeds faster and a larger amount of fuel can be burnt (high IL). On the contrary, for cycles where ignition occurs late (high LD), a leaner mixture is found around the glow plug due to the EoI, and thus a smaller amount of fuel is burnt (low IL). With regard to the parametric variation, CFD results show that an increase on injected mass or rail pressure leads to a clear decrease in the maximum equivalence ratio in the glow plug vicinity. This shows that a short injection pulse at low rail pressure results in a more favorable vaporization process, which should creates richer mixtures close to the glow plug and is more favorable for ignition according to chemical calculations. This trend correlates very well with the experimental results.

In order to get a better understanding of the fuel evolution near the glow plug, processes during and after injection are illustrated in Figure 17. This figure shows the temporal evolution of the fuel droplets and the air velocity (vectors) on the spray symmetry plane for the same injected mass of fuel at 
two different values of rail pressure. The figure shows that the spray grows with time as injection progresses and a vortex develops, indicating the air entrainment process into the spray. During this period, fuel flow is driven by injection. After EoI, there is a strong deceleration of the spray starting from the nozzle hole that spreads over the whole spray very fast. Later fuel movement is mainly driven by the air vortex developed during injection. The images show fuel droplets moving toward the glow plug, causing the transient maximum in equivalence ratio (at around $1000 \mu s$ ) observed in Figure 16. If the rail pressure is higher, fuel spray momentum is higher, which means that fuel reaches much faster the bowl wall, away from the glow plug area. This is quite evident comparing the situation for both rail pressure values at EoI (800 $\mu s$ for the lower rail pressure, and $667 \mu s$ for the higher one). This means that the same amount of injected fuel mass is distributed in a wider region. Consequently, later fuel transport toward the glow plug can carry only a smaller amount of fuel, resulting in leaner maximum equivalence ratio values, as observed in Figure 16. If the amount of fuel mass is larger at the same rail pressure, the effect is similar. Higher velocities are reached during and at the end of injection as a result of higher injection velocities (Figure 10) which provokes that a larger amount of fuel misses the glow plug area compared with the shorter injection case.

\section{Summary and conclusions}

An optical engine that reproduces typical in-cylinder thermodynamic conditions of a real passenger car engine during glow-plug assisted start at very low temperature $\left(-20^{\circ} \mathrm{C}\right)$ has been used for systematic experiments. Cold 
start combustion process has been described throughout this paper and the parameters with major influence have been identified.

Cold start combustion is characterized by high cycle to cycle dispersion which is the result of lack of control on ignition for being on the limit between combustion and misfiring. Under such conditions, injection settings, specifically rail pressure and injection duration, do have an influence on ignition success. Injection strategies with low pressure and short duration are favorable to create a strong pilot flame on the spray closest to the glow plug, due to a better transport of fuel towards the glow plug after the end of injection.

Main combustion starts from pilot flame, and propagates to the rest of the combustion chamber promoted by the turbulent motion generated by the injection event. During injection, a strong visible flame is observed due to high local equivalence ratios, most probably due to soot. After end of main injection, the rapid leaning of the mixture suppresses the typical strong soot radiation, and $\mathrm{OH} \mathrm{UV}$ radiation is observed to end the combustion process in regions far from the glow plug. Under these conditions not all the injected fuel is burnt, even for highest IMEP cases.

\section{Acknowledgements}

Authors thank the Spanish Ministry of Innovation and Science for the financial support through the project OPTICOMB (reference code: TRA200767961-C03-C01). Authors also thank Daniel Lérida Sánchez de las Heras for his outstanding work in the facility set-up and adaptation and for his support during the tests. 


\section{References}

[1] Weilenmann M, Favez Jean-Yves, Alvarez R. Cold-start emissions of modern passenger cars at different low ambient temperatures and their evolution over vehicle legislation categories. Atmospheric Environment $2009 ; 43: 2419-2429$.

[2] Lindl B, Schmitz Heinz-Georg. Cold-start equipment for diesel directinjection engines. SAE Paper 1999-01-1244; 1999.

[3] Payri F, Broatch A, Serrano J R, Rodríguez L F, Esmorís A. Study of the Potential of Intake Air Heating in Automotive DI Diesel Engines. SAE Paper 2006-01-1233; 2006.

[4] Broatch A, Ruiz S, Margot X, Gil A. Methodology to estimate the threshold in-cylinder temperature for self-ignition of fuel during cold start of Diesel engines. Energy 2010; 35:2251-2260.

[5] Pacaud P, Perrin H, Laget O. Cold Start on Diesel Engine: Is Low Compression Ratio Compatible with Cold Start Requirements? SAE Paper 2008-01-1310; 2008.

[6] Laget O, Pacaud P, Perrin H. Cold start on low compression ratio diesel engine: experimental and 3D RANS computation investigations. Oil and Gas Science and Technology Rev. IFP 2009; 64: 407-429.

[7] MacMillan D, La Rocca A, Shayler P J, Murphy M, Pegg I G. The Effect of Reducing Compression Ratio on the Work Output and Heat Release Characteristics of a DI Diesel under Cold Start Conditions. SAE Paper 2008-01-1306; 2008. 
[8] Henein N A, Zahdeh A R, Yassine M K, Bryzik W. Diesel engine cold starting: combustion instability. SAE Paper 920005; 1992.

[9] Zahdeh A R, Henein N A, Bryzik W. Diesel cold starting Actual cycle analysis under border-line conditions. SAE Paper 900441; 1990.

[10] Osuka I, Nishimura M, Tanaka Y, Miyaki M. Benefits of new fuel injection system technology on cold startability of diesel engines Improvements on cold startability and white smoke reduction by means of multi injection with common rail fuel system (ECD-U2). SAE Paper 940586; 1994.

[11] Perrin H, Dumas J P, Laget O, Walter B. Analysis of Combustion Process in Cold Operation with a Low Compression Ratio Diesel Engine. SAE Paper 2010-01-1267; 2010.

[12] Chartier C, Aronsson U, Andersson Ö, Egnell R. Effect of injection strategy on cold start performance in an optical Light-Duty DI diesel engine. SAE Paper 2009-24-0045; 2009.

[13] Pastor J V, García-Oliver J M, Pastor J M, Ramírez-Hernández J G. Experimental facility and methodology for systematic studies of cold startability in direct injection diesel engines. Measurement Science and Technology 2009; 20: 09519.

[14] Lapuerta M, Armas O, Hernández J J. Diagnosis of DI Diesel combustion from in-cylinder pressure signal by estimation of mean thermodynamic properties of the gas. Applied Thermal Engineering 1999; 19: 513-529. 
[15] Payri F, Molina S, Martín J, Armas O. Influence of measurement errors and estimated parameters on combustion diagnosis. Applied thermal engineering 2006; 26: 226-236.

[16] Siebers D L, Higgins B S. Effects of injector conditions on the flame lift-off length of DI Diesel sprays. In: Whitelaw J H, Payri F, Desantes J M. Thermo- and fluid dynamic processes in diesel engines. Springer. ISBN: 978-3-540-42665-3.

[17] Pickett L M, Siebers D L. Soot in diesel fuel jets: effects of ambient temperature, ambient density, and injection pressure. Combustion and Flame 2004; 138: 114-135.

[18] Kee R J, Rupley F M, Miller J A. Chemkin II: A Fortran Chemical Kinetics Package for the Analysis of a Gas-Phase Chemical Kinetics. Tech. report: Sandia Laboratories 1993.

[19] Curran H J, Gaffuri P, Pitz W J, Westbrook C K. A comprehensive modeling study of n-Heptane oxidation. Combustion and Flame 1998; 114: $149-177$.

[20] Star-CD Methodology, Version 3.26. CD-Adapco; 2005.

[21] Dukowicz J K. A particle-fluid numerical model for liquid sprays. Journal of Computational Physics 1980; 35: 229-253.

[22] Huh K Y, Gosman A D. A phenomenological model of diesel spray atomization. Proceedings of the International Conference on Multiphase Flows; 1991. 
[23] Reitz R D, Diwakar R. Structure of high-pressure fuel sprays. SAE Paper $870598 ; 1987$.

[24] Habchi C, Lafossas F A, Beard P, Broseta D. Formulation of a oneComponent fuel lumping model to assess the effects of fuel thermodynamic properties on internal combustion engine mixture preparation and combustion. SAE Paper 2004-01-1996; 2004.

[25] Heywood J B. Internal combustion engine fundamentals. McGraw-Hill, Inc.; 1988.

[26] Musculus M. Entrainment waves in decelerating transient turbulent jets. J. Fluid Mech. 2009; 638: 117-140. 


\section{List of Figures}

1 Sketch of the optical access in the single cylinder engine and an image showing how the combustion chamber is seen from the camera point of view. 1.- Glow plug, 2.- Injector nozzle, 3.- Pressure transducer, 4.- Aluminum piece, 5.- Sapphire window, 6.- Elongated piston, 7.- Elliptical UV mirror. . . . . 29

$2 \quad I_{\text {cumul }}$ as a function of time for a pilot injection test. The LD is defined as the time from SoI to flame appearance. And, IL is defined as the area under the $I_{\text {cumul }}$ trace. . . . . . . . . . 30

3 3D view of an axial cut of the computational mesh built for the CFD calculations. The red lines represent the limits of the combustion chamber. And, the further refined volume around the glow plug can also be observed. . . . . . . . . . . . . 31

4 IMEP, SOC and CE versus the repetition number for a 30 repetitions test. Rail pressure is 250 bar and a pilot + main injection strategy, $6 \mathrm{mg}$ at $0 C A D$ and $24 \mathrm{mg}$ at $5 C A D$, is used. EoI $I_{\text {main }}$ is plotted on the $\mathrm{SOC}$ axis as a reference of the injection duration. . . . . . . . . . . . . . . 32

5 Image sequence acquired with the high speed camera and illuminating with an external light source for a combustion cycle. Pilot injection $(6 \mathrm{mg})$ starts at $0 C A D$ and main injection $(24 \mathrm{mg})$ starts at $5 C A D$. Rail pressure 370 bar. In the topleft corner of each image the acquisition time ASoI and the crank angle position at which each image was acquired are shown. . . . . . . . . . . . . . . . . . . 33

6 Left: LD and IL versus repetition number for a single pilot injection test with 20 repetitions. $6 \mathrm{mg}$ are injected at TDC with a rail pressure of 250 bar. Right: Location of the first luminosity spot detected plotted in polar coordinates; the red ellipse is a sketch of the glow plug. . . . . . . . . . . . . . 34 
7 Injection pulse, ROHR and $I_{\text {cumul }}$ as a function of the crank angle position. And selected images of a combustion cycle with 250 bar of rail pressure, pilot injection of $6 \mathrm{mg}$ injected at $0 C A D$ and main pulse of $24 \mathrm{mg}$ at $5 C A D$. Figures at the bottom of the image are referenced with respect to SoI, and the black lines point out at the corresponding ROHR. White-radial lines on the images correspond to the approximate locations of the sprays. . . . . . . . . . . . .

8 Images corresponding to two combustion cycles with identical engine settings but different camera set-up. In the top, four selected images of broadband luminosity (NL); and in the bottom, four selected images of $\mathrm{OH}$ radiation. Acquisition time (ASoI) and its corresponding crank angle position are shown in the top-right corner of each image. . . . . . . . . . . . . . 36

9 IMEP, SOC and CE versus the repetition number for a 30 repetitions test. The rail pressure is 370 bar of rail pressure and a pilot + main injection strategy, $6 \mathrm{mg}$ at $0 C A D$ and $24 \mathrm{mg}$ at $5 C A D$, is used. EoI main is plotted on the SOC axis as a reference of the injection duration. . . . . . . . . . . 37

10 Injection pulse, ROHR and $I_{\text {cumul }}$ as a function of the crank angle position. And selected images of a combustion cycle with 370 bar of rail pressure, pilot injection of $6 \mathrm{mg}$ injected at $0 C A D$ and main pulse of $24 \mathrm{mg}$ at $5 C A D$. Figures at the bottom of the image are referenced with respect to SoI, and the black lines point out at the corresponding ROHR. White-radial lines on the images correspond to the approximate locations of the sprays. . . . . . . . . . . . . 38

11 Injection rate as a function of time for three different amounts of injected mass per orifice $(0.43,0.86$ and $1.71 \mathrm{mg})$ and two levels of rail pressure $(250$ and 370 bar $)$. . . . . . . . . . 39

12 Pilot probability as a function of the injected mass per orifice for two levels of rail pressure, 250 and 370 bar. . . . . . . . . . 40

13 Box-Whisker plots of LD versus the injected mass per orifice for two levels of rail pressure. 250 bar in the left and 370 bar in the right. Unfilled dots represent the outliers which have been calculated with a factor of 1.5 times the interquartile range. 41 
14 Box-Whisker plots of IL versus the injected mass per orifice for two levels of rail pressure. $250 \mathrm{bar}$ in the left and $370 \mathrm{bar}$ in the right. Unfilled dots represent the outliers which have been calculated with a factor of 1.5 times the interquartile range. 42

15 n-Heptane predicted ignition delay as a function of equivalence ratio and temperature at a constant pressure of 27 bar. . . . . 43

16 Temporal evolution of injection rate and CFD predicted equivalence ratio for the vapor phase of the near-plug zone for three different strategies: the baseline case $(0.86 \mathrm{mg}$ per orifice, 250 bar), a $1.71 \mathrm{mg}$ per orifice injection at the same rail pressure and a $0.86 \mathrm{mg}$ per orifice injection at $370 \mathrm{bar}$. . . . . . . 44

17 CFD figures showing the fuel droplets and air velocity (vectors) evolution in a section which contains the cylinder and closest to glow plug spray axes. A pilot injection of $0.86 \mathrm{mg}$ per orifice at two rail pressures, 250 bar in the left and 370 bar in the right. The corresponding time ASoI of each pair of figures is shown in the left side edge. And in the bottom-right corner of each image the maximum fuel velocity is also shown. As this plane does not contain the glow plug, its approximated location is signaled with blue lines. . . . . . . . . . . . 45 

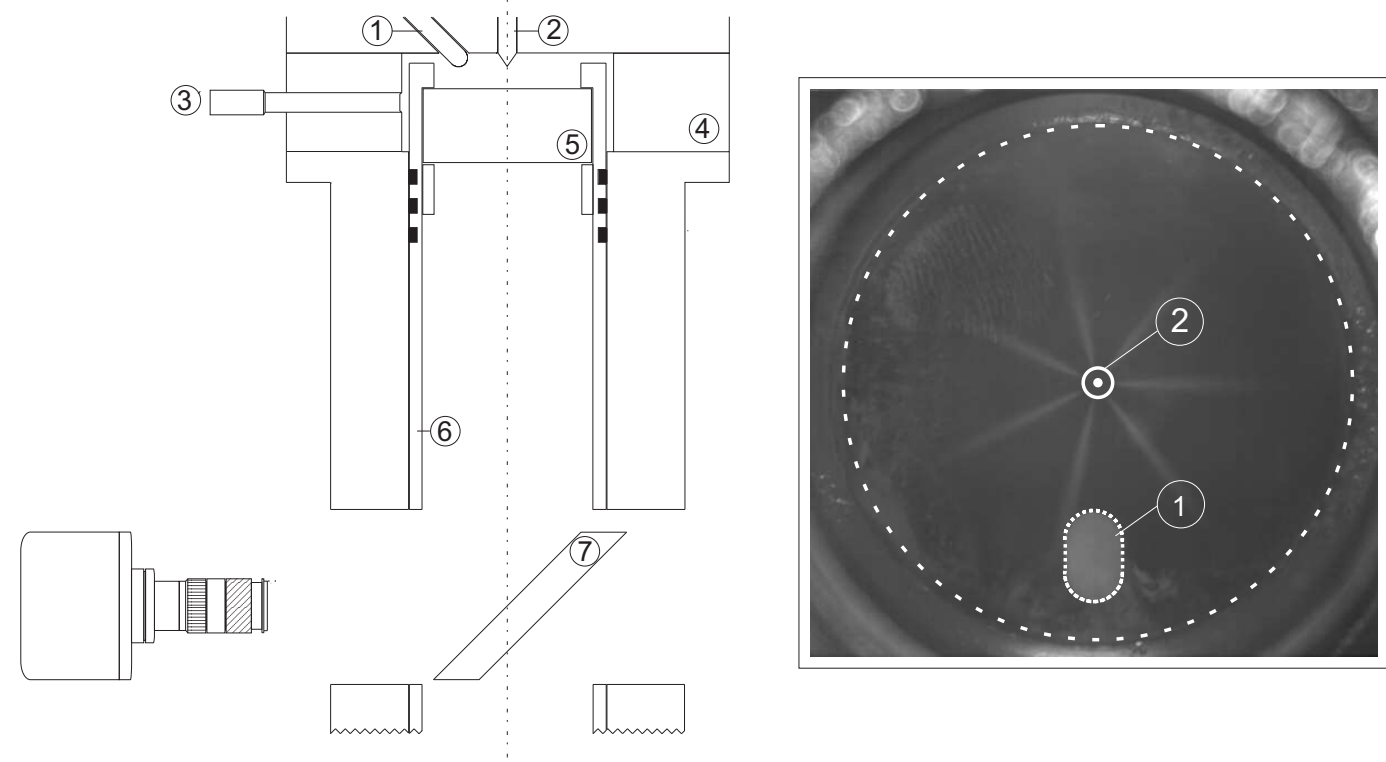

Figure 1: Sketch of the optical access in the single cylinder engine and an image showing how the combustion chamber is seen from the camera point of view. 1.- Glow plug, 2.Injector nozzle, 3.- Pressure transducer, 4.- Aluminum piece, 5.- Sapphire window, 6.Elongated piston, 7.- Elliptical UV mirror. 


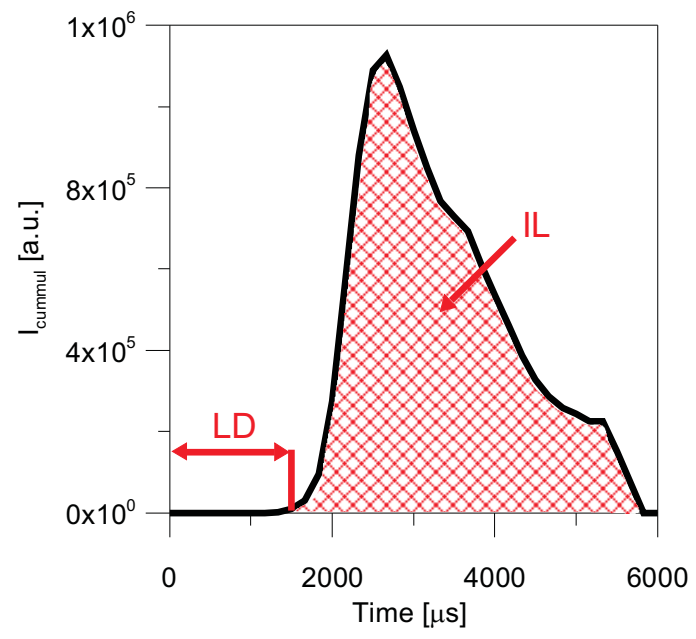

Figure 2: $I_{\text {cumul }}$ as a function of time for a pilot injection test. The LD is defined as the time from SoI to flame appearance. And, IL is defined as the area under the $I_{\text {cumul }}$ trace. 


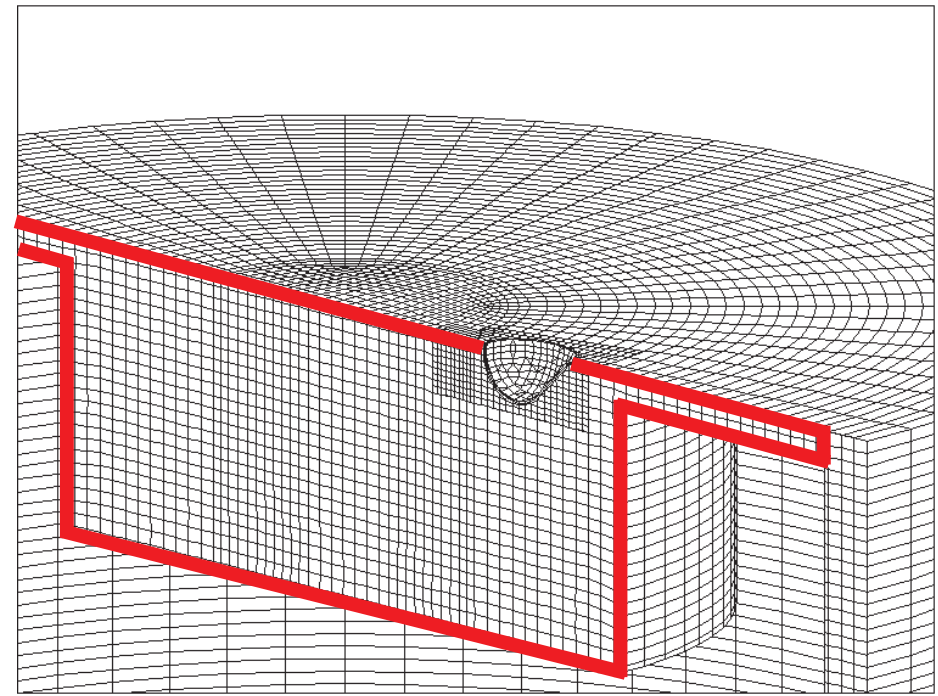

Figure 3: 3D view of an axial cut of the computational mesh built for the CFD calculations. The red lines represent the limits of the combustion chamber. And, the further refined volume around the glow plug can also be observed. 


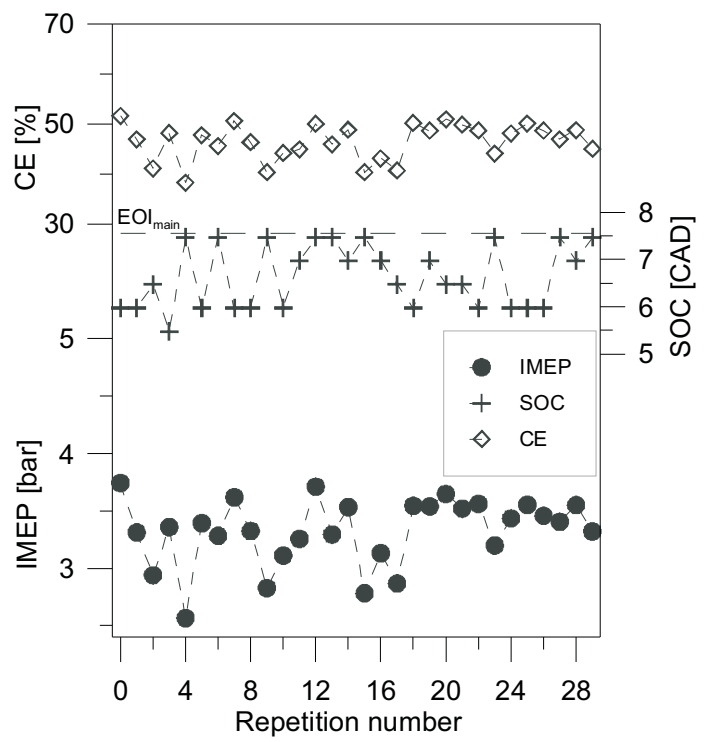

Figure 4: IMEP, SOC and CE versus the repetition number for a 30 repetitions test. Rail pressure is $250 \mathrm{bar}$ and a pilot + main injection strategy, $6 \mathrm{mg}$ at $0 C A D$ and $24 \mathrm{mg}$ at $5 C A D$, is used. EoI main is plotted on the SOC axis as a reference of the injection duration. 

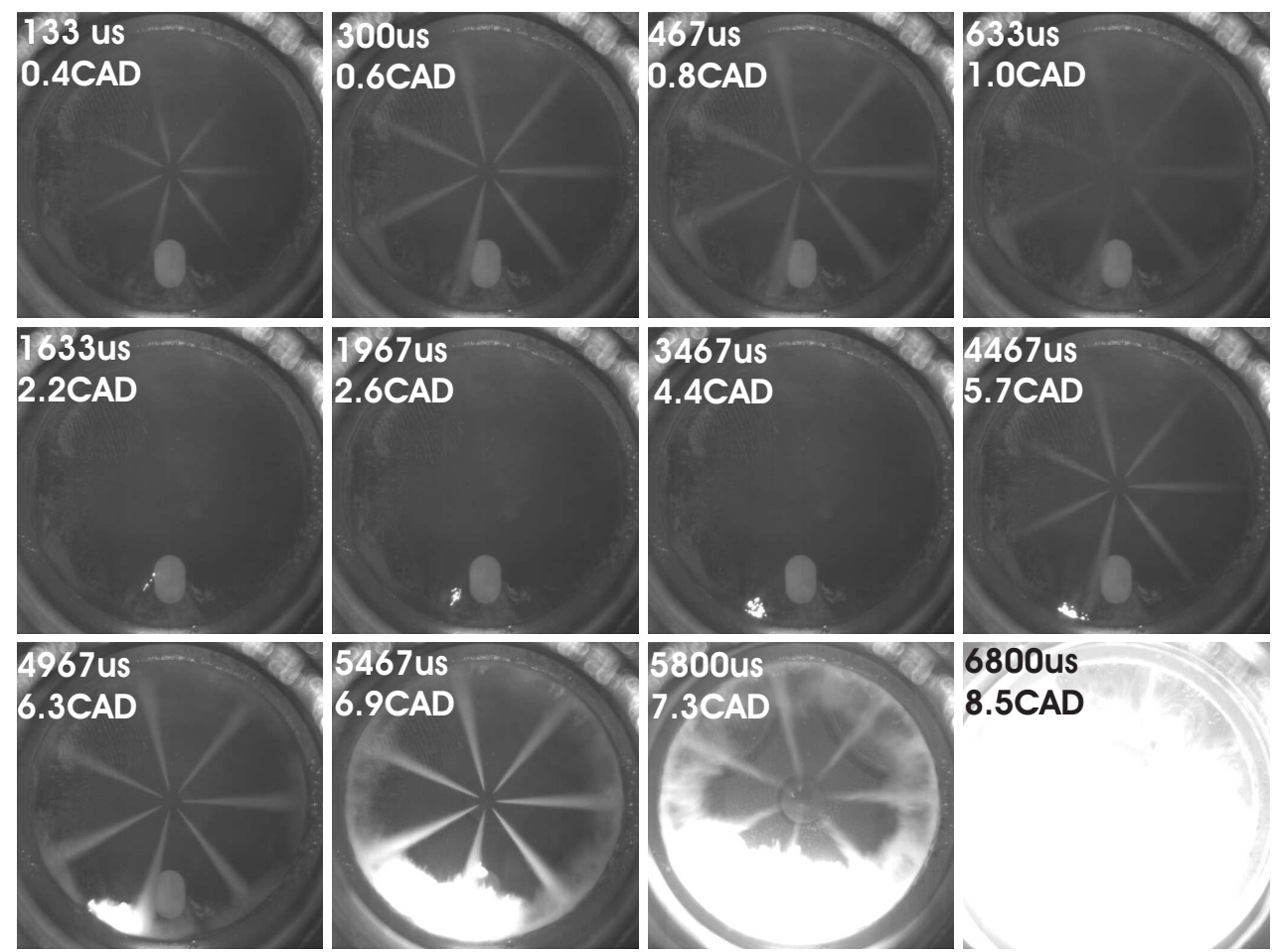

8.5CAD

Figure 5: Image sequence acquired with the high speed camera and illuminating with an external light source for a combustion cycle. Pilot injection $(6 \mathrm{mg})$ starts at $0 C A D$ and main injection $(24 \mathrm{mg})$ starts at $5 C A D$. Rail pressure $370 \mathrm{bar}$. In the top-left corner of each image the acquisition time ASoI and the crank angle position at which each image was acquired are shown. 


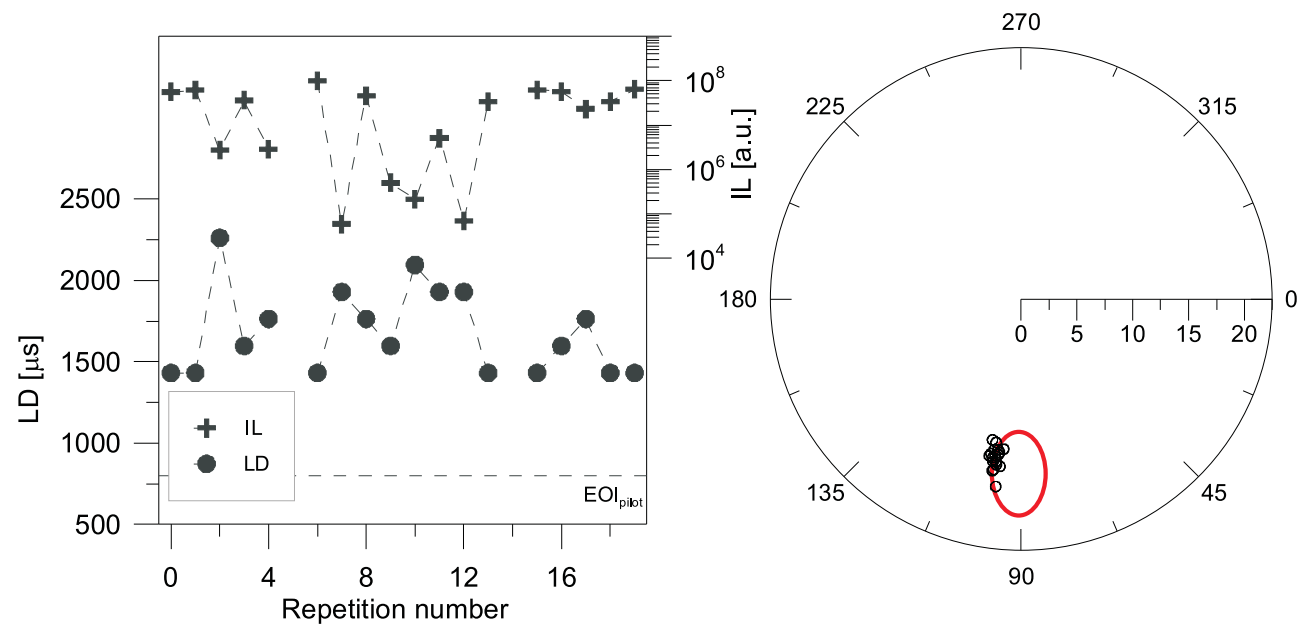

Figure 6: Left: LD and IL versus repetition number for a single pilot injection test with 20 repetitions. $6 \mathrm{mg}$ are injected at TDC with a rail pressure of 250 bar. Right: Location of the first luminosity spot detected plotted in polar coordinates; the red ellipse is a sketch of the glow plug. 

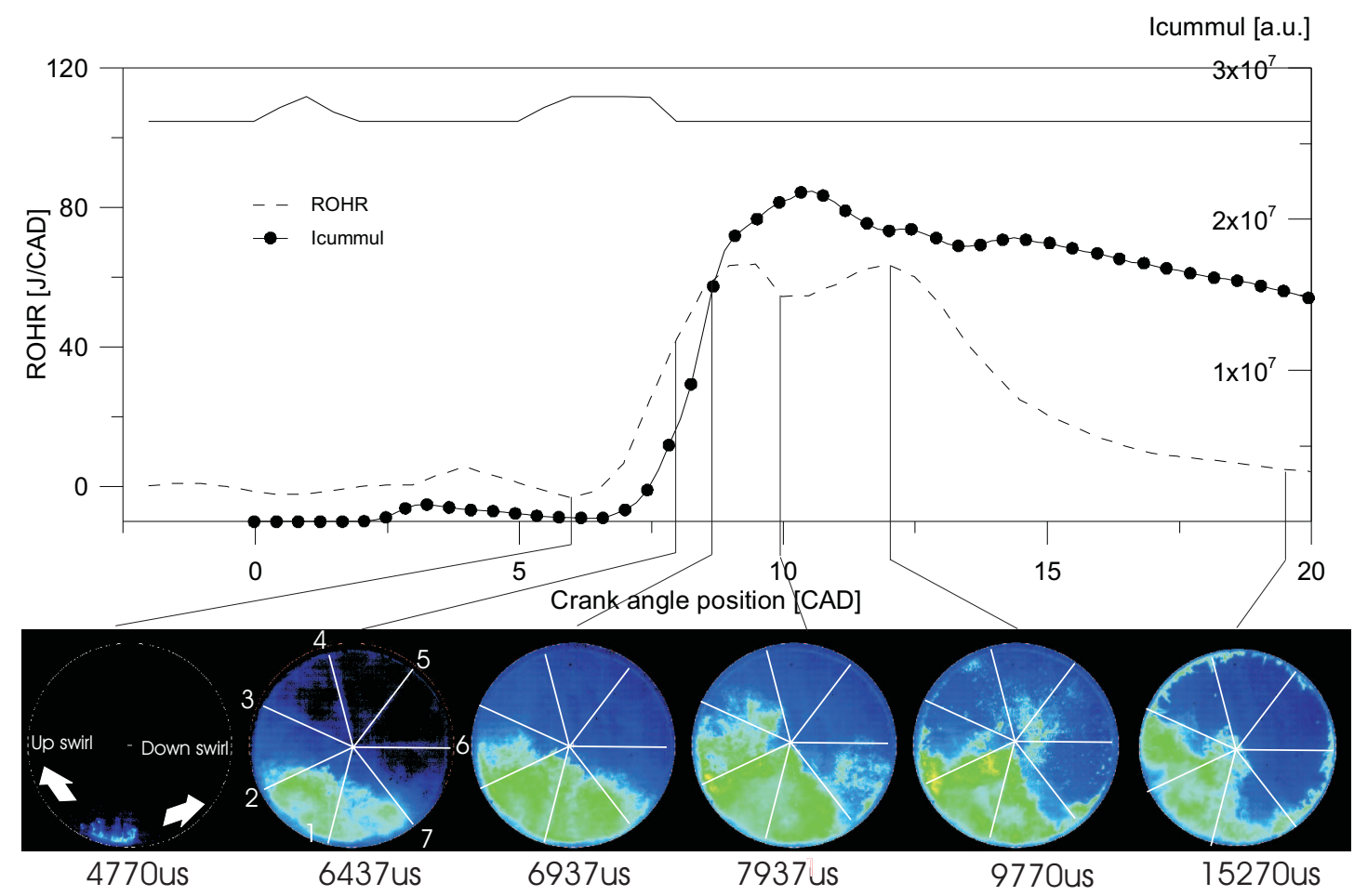

Figure 7: Injection pulse, ROHR and $I_{\text {cumul }}$ as a function of the crank angle position. And selected images of a combustion cycle with 250 bar of rail pressure, pilot injection of $6 \mathrm{mg}$ injected at $0 C A D$ and main pulse of $24 \mathrm{mg}$ at $5 C A D$. Figures at the bottom of the image are referenced with respect to SoI, and the black lines point out at the corresponding ROHR. White-radial lines on the images correspond to the approximate locations of the sprays. 


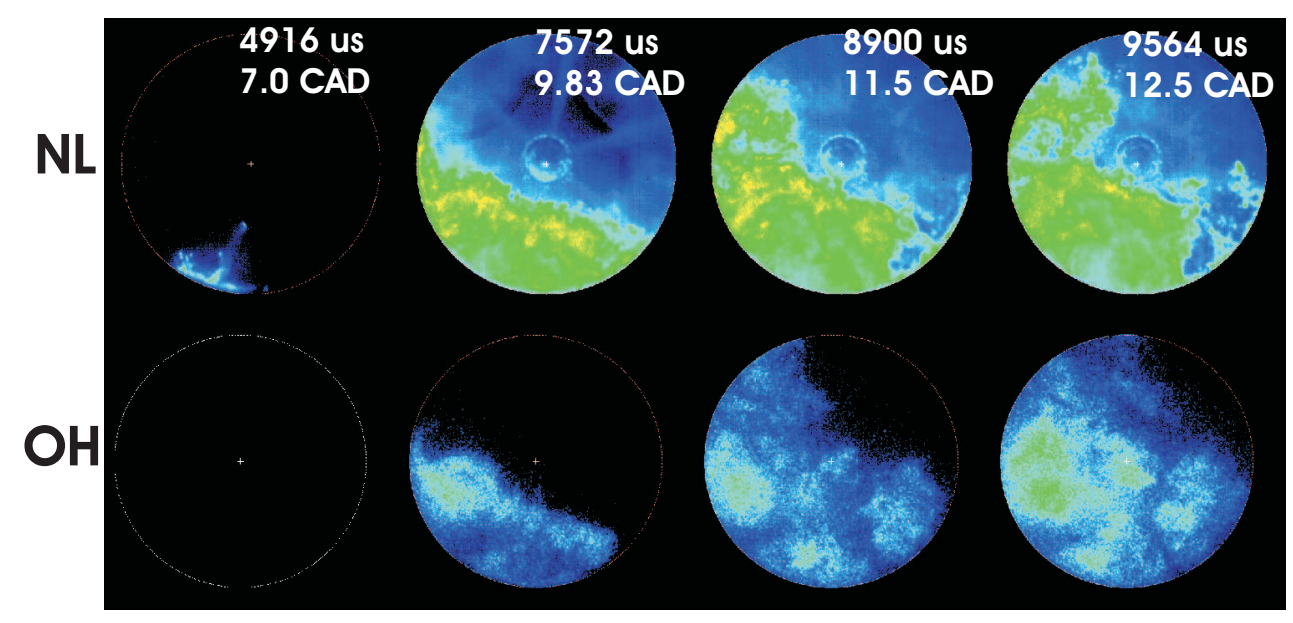

Figure 8: Images corresponding to two combustion cycles with identical engine settings but different camera set-up. In the top, four selected images of broadband luminosity $(\mathrm{NL})$; and in the bottom, four selected images of $\mathrm{OH}$ radiation. Acquisition time (ASoI) and its corresponding crank angle position are shown in the top-right corner of each image. 


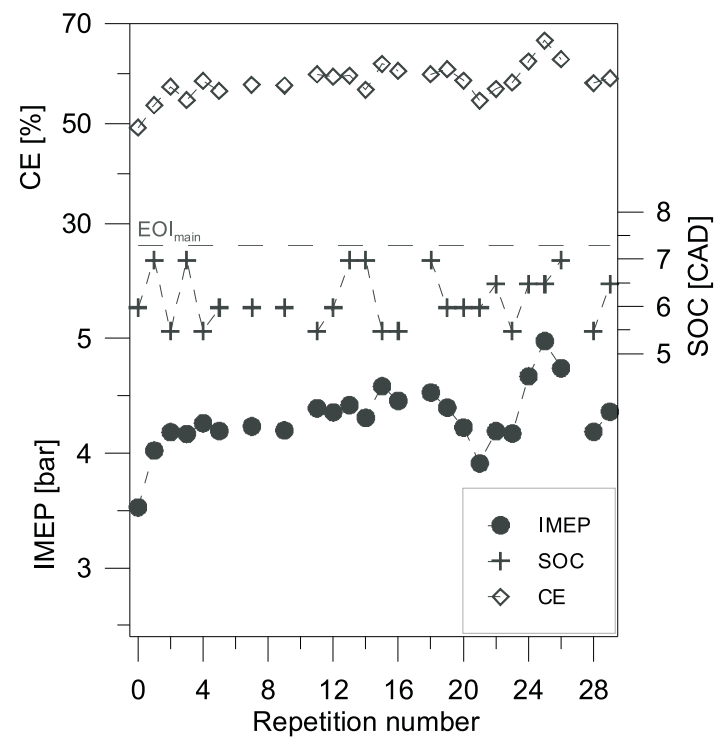

Figure 9: IMEP, SOC and CE versus the repetition number for a 30 repetitions test. The rail pressure is 370 bar of rail pressure and a pilot + main injection strategy, $6 \mathrm{mg}$ at $0 C A D$ and $24 \mathrm{mg}$ at $5 C A D$, is used. EoI $I_{\text {main }}$ is plotted on the $\mathrm{SOC}$ axis as a reference of the injection duration. 

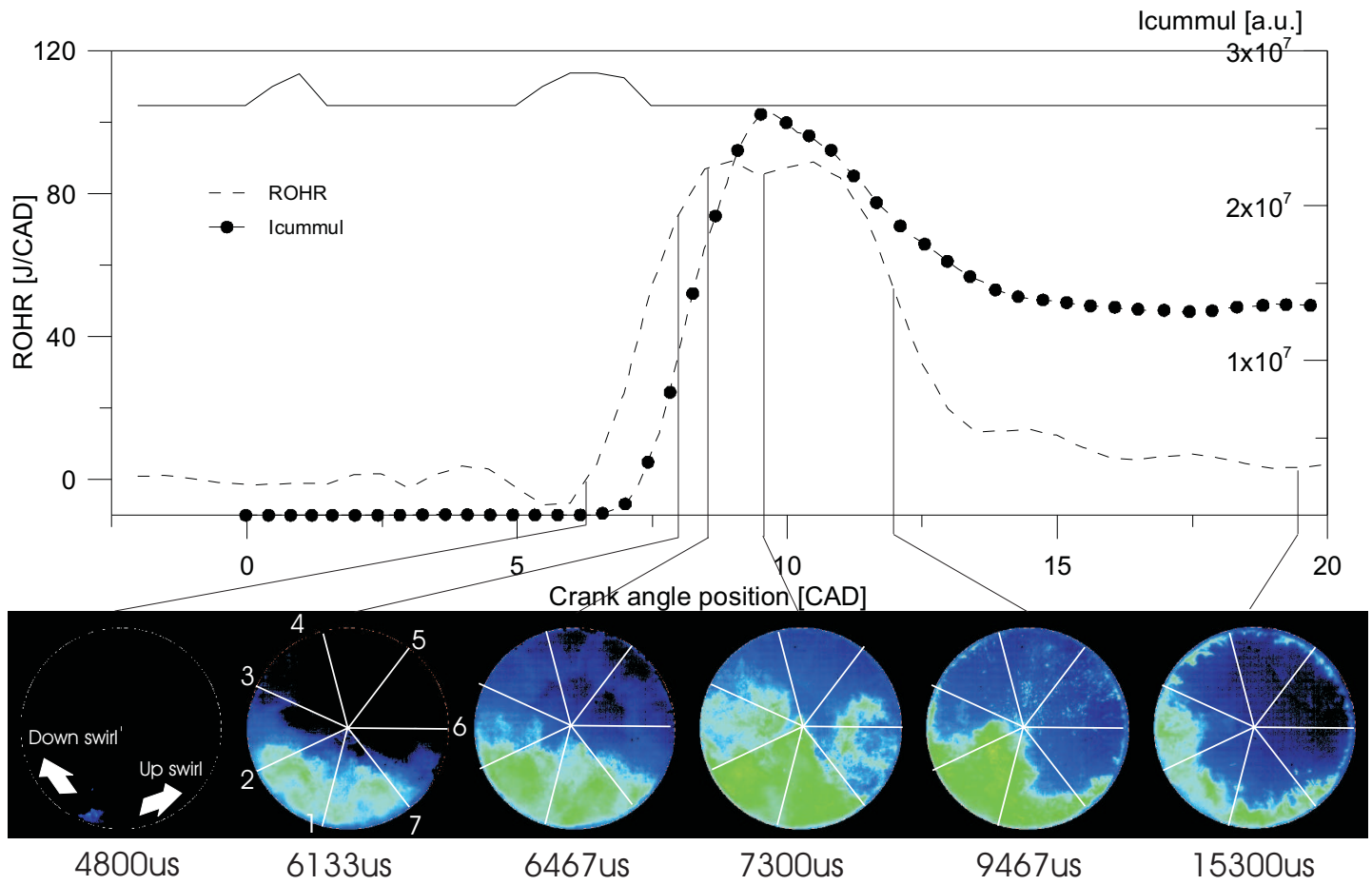

Figure 10: Injection pulse, ROHR and $I_{\text {cumul }}$ as a function of the crank angle position. And selected images of a combustion cycle with 370 bar of rail pressure, pilot injection of $6 \mathrm{mg}$ injected at $0 C A D$ and main pulse of $24 \mathrm{mg}$ at $5 C A D$. Figures at the bottom of the image are referenced with respect to SoI, and the black lines point out at the corresponding ROHR. White-radial lines on the images correspond to the approximate locations of the sprays. 


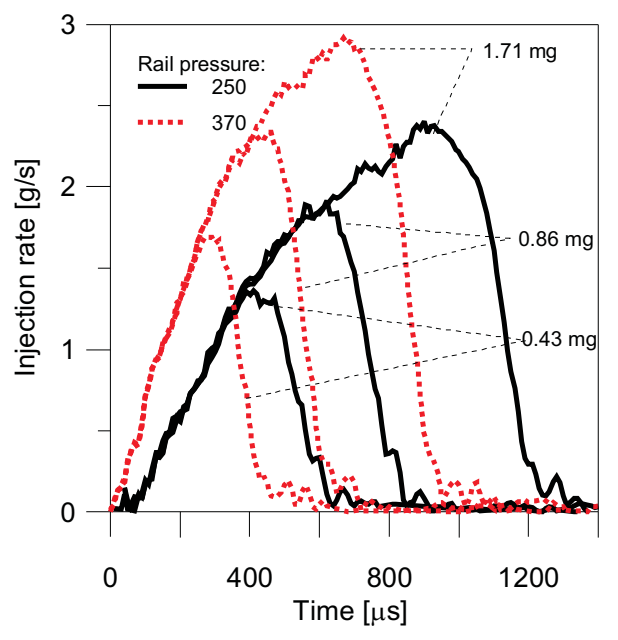

Figure 11: Injection rate as a function of time for three different amounts of injected mass per orifice $(0.43,0.86$ and $1.71 \mathrm{mg})$ and two levels of rail pressure $(250$ and $370 \mathrm{bar}$ ). 


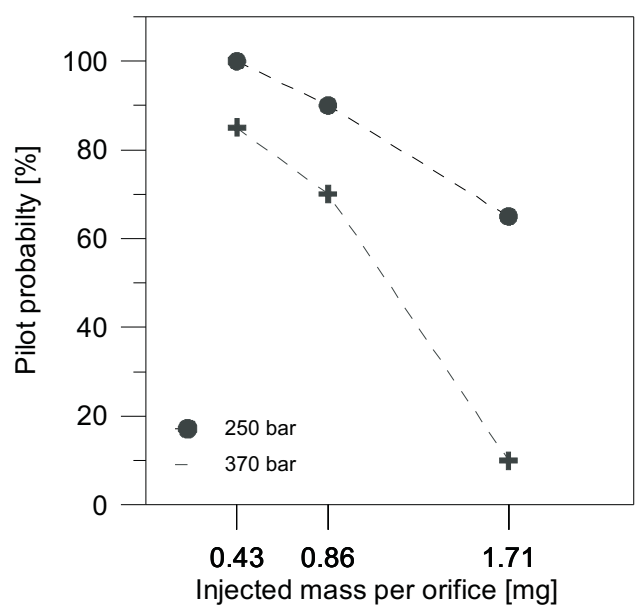

Figure 12: Pilot probability as a function of the injected mass per orifice for two levels of rail pressure, 250 and 370 bar. 

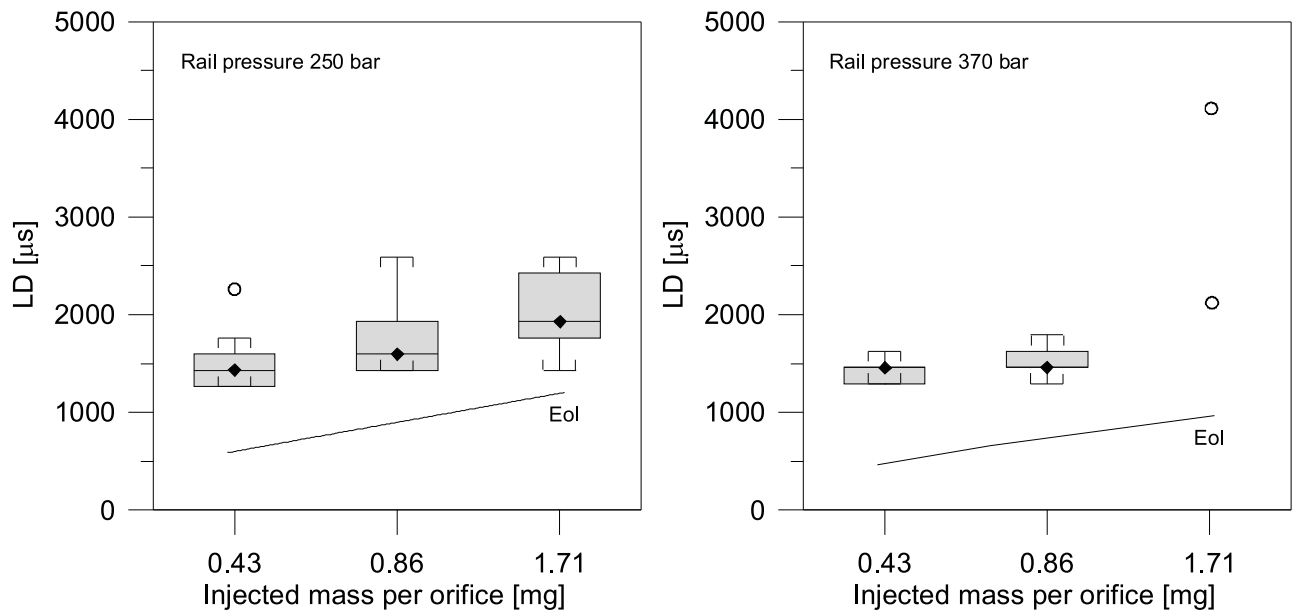

Figure 13: Box-Whisker plots of LD versus the injected mass per orifice for two levels of rail pressure. 250 bar in the left and 370 bar in the right. Unfilled dots represent the outliers which have been calculated with a factor of 1.5 times the interquartile range. 

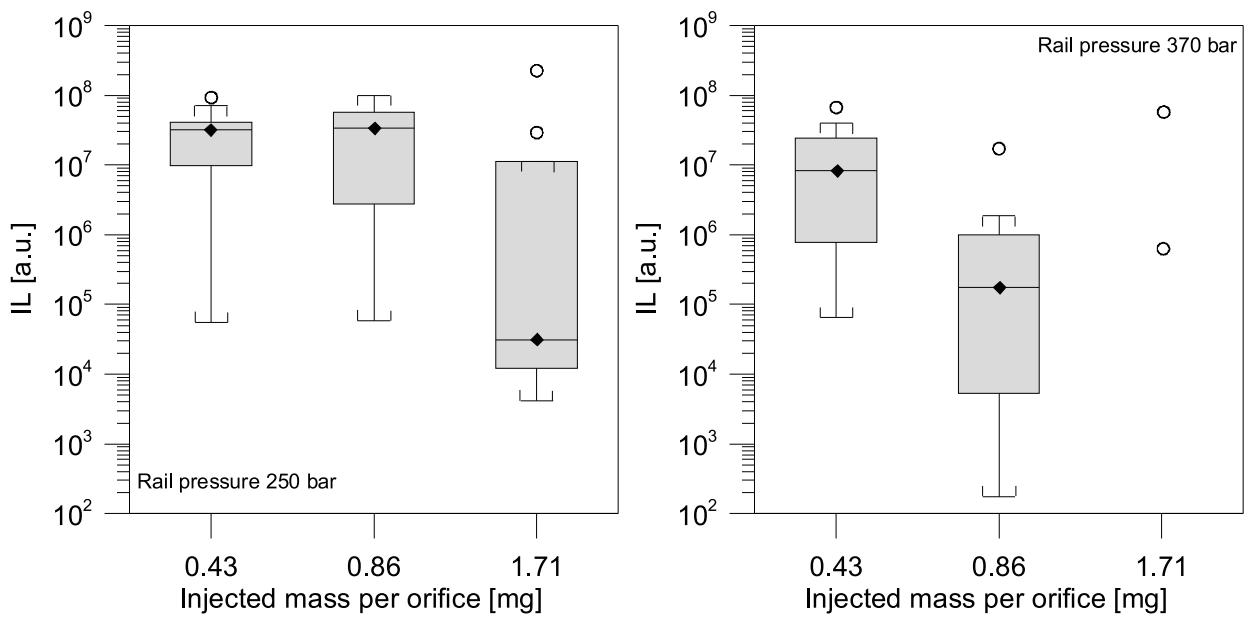

Figure 14: Box-Whisker plots of IL versus the injected mass per orifice for two levels of rail pressure. 250 bar in the left and 370 bar in the right. Unfilled dots represent the outliers which have been calculated with a factor of 1.5 times the interquartile range. 


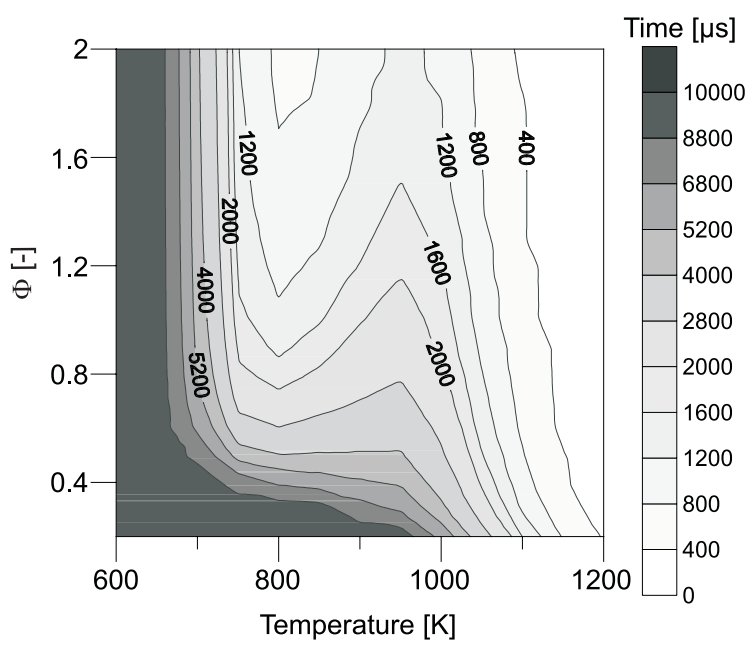

Figure 15: n-Heptane predicted ignition delay as a function of equivalence ratio and temperature at a constant pressure of 27 bar. 


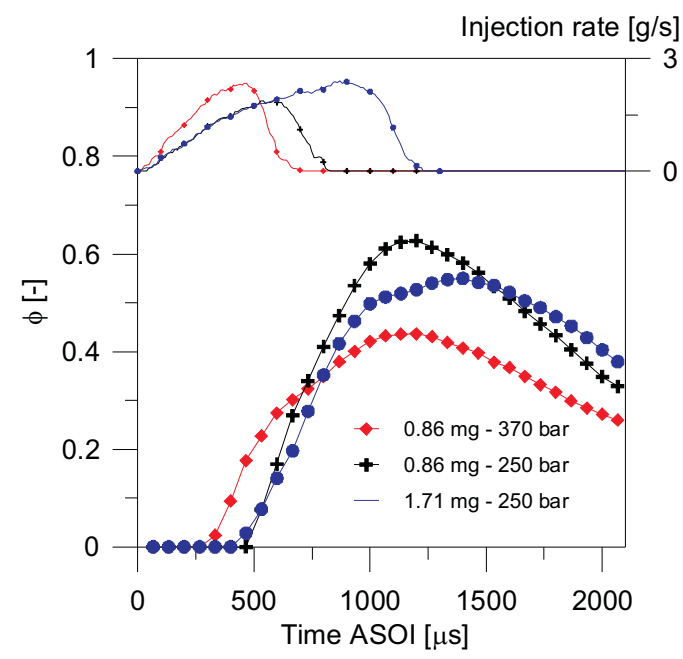

Figure 16: Temporal evolution of injection rate and CFD predicted equivalence ratio for the vapor phase of the near-plug zone for three different strategies: the baseline case (0.86 $\mathrm{mg}$ per orifice, $250 \mathrm{bar}$ ), a $1.71 \mathrm{mg}$ per orifice injection at the same rail pressure and a $0.86 \mathrm{mg}$ per orifice injection at $370 \mathrm{bar}$. 


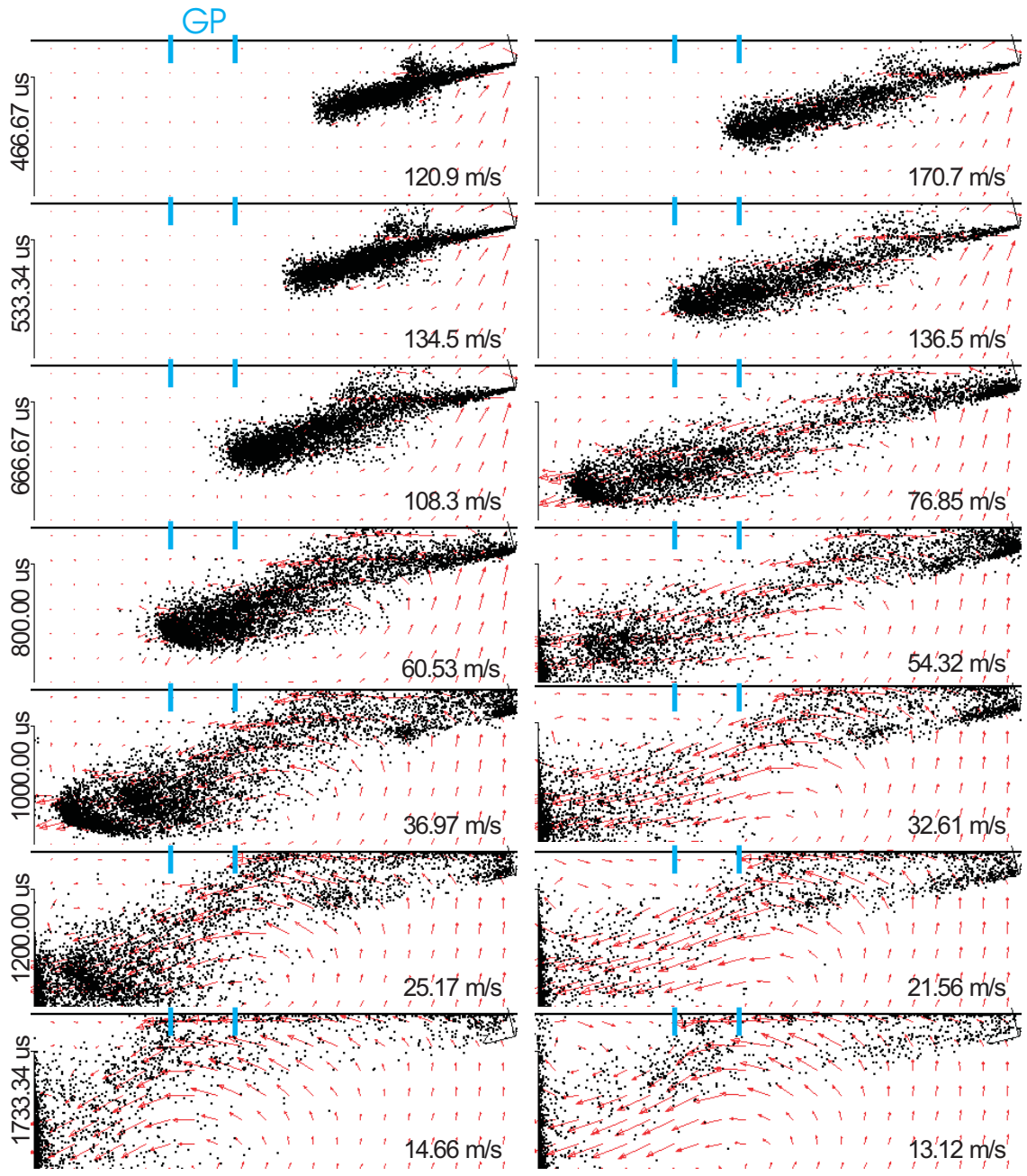

Figure 17: CFD figures showing the fuel droplets and air velocity (vectors) evolution in a section which contains the cylinder and closest to glow plug spray axes. A pilot injection of $0.86 \mathrm{mg}$ per orifice at two rail pressures, 250 bar in the left and 370 bar in the right. The corresponding time ASoI of each pair of figures is shown in the left side edge. And in the bottom-right corner of each image the maximum fuel velocity is also shown. As this plane does not contain the glow plug, its approximated location is signaled with blue lines. 


\section{List of Tables}

1 Abbreviations ................... . . . 47 
Table 1: Abbreviations

\begin{tabular}{|c|c|c|}
\hline \multicolumn{3}{|l|}{ Nomenclature } \\
\hline I light intensity, dimensionless & $\mathrm{EVO}$ & exhaust valve opening \\
\hline $\mathrm{m} \quad$ mass, $\mathrm{kg}$ & FWHM & full width half maximum \\
\hline Subscripts & HRL & heat release law \\
\hline cummul accumulated & & integrated luminosity \\
\hline fuel & IMEP & indicated mean effective pressure \\
\hline main injection & IVC & intake valve closing \\
\hline pilot injection & LD & luminosity delay \\
\hline Abbreviations & LHV & lower heating value \\
\hline ASoI after start of injection & NL & natural luminosity \\
\hline crank angle degree & ROHR & rate of heat release \\
\hline combustion efficiency & SOC & start of combustion \\
\hline computational fluid dynamics & SoI & start of injection \\
\hline compression ratio & TDC & top dead centre \\
\hline engine control unit & UV & ultraviolet \\
\hline
\end{tabular}

